\title{
Identification of gene pathways altered by deletion of the androgen receptor specifically in mineralizing osteoblasts and osteocytes in mice
}

\author{
Patricia K Russell, Michele V Clarke, Jarrod P Skinner, Tammy P S Pang, Jeffrey D Zajac \\ and Rachel A Davey
}

Department of Medicine, Austin Health, University of Melbourne, Studley Road, Heidelberg, Victoria 3084, Australia

(Correspondence should be addressed to R A Davey; Email: r.davey@unimelb.edu.au)

\begin{abstract}
Androgens play a key role in skeletal growth and maintenance in males and can mediate their actions, at least in part, via the androgen receptor (AR) in osteoblasts. To investigate the mechanisms by which androgens exert their effects via the $\mathrm{AR}$ in mineralizing osteoblasts and osteocytes, we identified gene targets/pathways regulated by the AR using targeted gene expression and microarray approaches on bone isolated from mice in which the AR is specifically deleted in mineralizing osteoblasts and osteocytes (mOBL-ARKOs). Gene ontology mining indicated a number of biological processes to be affected in the bones of mOBL-ARKOs including skeletal and muscular system development and carbohydrate metabolism. All genes identified to have altered expression in the bones of mOBL-ARKOs were confirmed by Q-PCR for their androgen responsiveness in an androgen deprivation and replacement mouse model. The osteoblast genes Col1a1 and Bglap and the osteoclast genes Ctsk and RANKL (Tnfs11) were upregulated in the bones of mOBLARKOs, consistent with the increased matrix synthesis, mineralization, and bone resorption observed previously in these mice. Of significant interest, we identified genes involved in carbohydrate metabolism (adiponectin and Dpp4) and in growth and development (GH, Tgfb (Tgfb2), Wnt4) as potential targets of androgen action via the AR in mineralizing osteoblasts.
\end{abstract}

Journal of Molecular Endocrinology (2012) 49, 1-10

\section{Introduction}

Androgens are essential for skeletal growth and bone accrual during puberty (Vanderschueren et al. 2004) and for bone maintenance post-puberty in males (Basaria \& Dobs 2001), determining both the strength and size of adult bone (Wiren 2005). We and others have shown that global deletion of the androgen receptor (AR) in mice results in bones of reduced size and cortical thickness, with decreased trabecular bone volume compared with control males (Yeh et al. 2002, Kawano et al. 2003, Venken et al. 2006, MacLean et al. 2010), indicating that these important actions of androgens are via the AR in bone and not through aromatization to estrogen and action via the estrogen receptor. However, the exact mechanism by which androgens exert these actions via the AR on bone remains unclear.

There is convincing evidence in the literature indicating that the effects of androgens on bone are mediated, at least in part, by the AR expressed on osteoblasts (Colvard et al. 1989, Kasperk et al. 1989). There are three distinct stages of osteoblast development: proliferation, matrix development and maturation, and mineralization of the bone matrix
(Owen et al. 1990). During the bone formation process, a proportion of osteoblasts are embedded within the mineralized bone matrix, becoming osteocytes (Franz-Odendaal et al. 2006), which also express the AR (Abu et al. 1997). It is therefore conceivable that androgens may have different actions on osteoblasts at different stages of their development.

Insight into the role of androgens via the $\mathrm{AR}$ in osteoblasts at specific stages of their development has been gained by the use of genetically modified mouse models. Transgenic mice over-expressing the AR from the proliferating stage of osteoblast development, including those located at the periosteum, using the $3.6 \mathrm{~kb}$ Colla1 promoter, have increased periosteal apposition (Wiren et al. 2004). In contrast, overexpression of the $\mathrm{AR}$ in osteoblasts from late in the matrix development and maturation stage using the $2 \cdot 3 \mathrm{~kb}$ Colla1 promoter has no effect on bone size as measured by periosteal circumference (Wiren et al. 2008). Both AR transgenic models do, however, have a common phenotype of reduced formation at endocortical surfaces and increased trabecular bone volume as a result of reduced bone turnover (Wiren et al. 2004, 2008). Together, these data suggest that activation of the $\mathrm{AR}$ in immature osteoblasts mediates its anabolic 
effects on the periosteum, while AR action in both immature and mature osteoblasts inhibits bone formation at the endocortical surfaces while downregulating bone turnover within trabecular bone. Consistent with these findings, we have previously shown that deletion of the AR specifically in mineralizing osteoblasts and osteocytes in mOBL-ARKOs using the Cre/loxP system leads to trabecular and cortical bone loss due to increased bone resorption and an uncoupling of the bone matrix synthesis and mineralization processes, while bone size was not affected (Chiang et al. 2009).

We now extend our studies on the mOBL-ARKO mice in order to identify target genes/pathways in bone that are regulated either directly or indirectly by androgens acting via the $\mathrm{AR}$ in mineralizing osteoblasts and osteocytes. To achieve this, we used two approaches. First, we used a targeted approach in which we determined the level of expression of genes expressed by osteoblasts, at defined stages of their development, and by osteoclasts, in the bones of mOBL-ARKOs and wild-type (WT) littermate controls. The second approach was to use microarray analysis to identify novel gene targets/pathways in bone regulated by the $\mathrm{AR}$ in mineralizing osteoblasts.

\section{Materials and methods}

\section{Mice}

The generation of the mOBL-ARKO mice used in this study has been described previously (Chiang et al. 2009). Briefly, mOBL-ARKOs were generated by breeding floxed AR mice (Notini et al. 2005) with osteocalcinCre mice (Chiang et al. 2009). mOBL-ARKOs were on a congenic C57BL/6 background. WT littermates were used as controls in all experiments. Genomic DNA isolated from tail biopsy was used as a template for PCR genotyping. The primer sequences used to detect the Cre transgene and the floxed AR allele have been described previously (Notini et al. 2007). Mice were supplied with water and standard chow containing $1.2 \%$ calcium and $0.96 \%$ phosphorous (Ridley Agriproducts, Corowa, NSW, Australia) ad libitum and were housed at $22{ }^{\circ} \mathrm{C}$ in a $12 \mathrm{~h}$ light: $12 \mathrm{~h}$ darkness cycle in standard cages. All procedures involving animals were approved by the Austin Health Animal Ethics Committee.

\section{Serum and bone collection}

WT and mOBL-ARKO mice were killed at 6 and 12 weeks of age by isoflurane anesthesia and cervical dislocation following a 4 or $12 \mathrm{~h}$ fast for 6- and 12-week-old mice respectively. Both tibia and femora were dissected and growth plates and all surrounding soft and connective tissue was removed. Cardiac blood was collected and serum was stored at $-20{ }^{\circ} \mathrm{C}$. In order to test the androgen responsiveness of those genes identified to be regulated in mOBL-ARKOs by microarray and gene expression analyses, 7-week-old WT male mice were randomly allocated into sham, orchidectomy (ORX) plus vehicle, or ORX plus dihydrotestosterone (DHT) treatment experimental groups. Empty control implants or DHT implants $(3 \times 1 \mathrm{~cm}$; Axell et al. 2006) were placed in the intra-abdominal fat layer at the time of surgery. At 10 weeks posttreatment, mice were killed by i.p. injection of $100 \mathrm{mg} / \mathrm{kg}$ sodium pentobarbitone and both tibiae were dissected and all surrounding soft and connective tissue was removed.

\section{RNA isolation and CDNA synthesis}

Total RNA was isolated from whole tibia and femur, including bone marrow but excluding growth plates, of WT and mOBL-ARKO male mice at 6 and 12 weeks of age and both tibiae of sham, ORX, and ORX plus DHT groups as described previously (Davey et al. 2000). Total RNA $(2 \mu \mathrm{g})$ was treated with two units of DNase I according to the manufacturer's instructions (DNA-Free Kit; Ambion, Austin, TX, USA). cDNA was synthesized from $1 \mu \mathrm{g}$ DNase-treated RNA using random hexamers (Promega) and M-MLV reverse transcriptase, according to the manufacturer's instructions (Promega).

\section{Microarray analysis}

Microarray analysis was performed by the Australian Genome Research Facility using the Affymetrix mouse genome 430 v2.0 array. This array uses more than 45000 probe sets to measure gene expression of more than 39000 transcripts and variants, including 34000 wellcharacterized genes. Five micrograms of total RNA from WT and mOBL-ARKO males at 6 and 12 weeks of age ( $n=3$ per group) were analyzed in duplicate. Normalization and differential gene expression analysis were carried out by the Australian Genome Research Facility using Partek Genomic Suite (Copyright Partek Inc., St Louis, MO, USA) and R/Bioconductor software (http://www.bioconductor.org). Genes were considered to be androgen responsive if expression was increased or decreased compared with controls by $\geq 1 \cdot 5$-fold $(P<0 \cdot 05)$. Pathways, processes, or functions that were over-represented in the androgen-responsive gene set were identified using the online Ingenuity pathway analysis tool (http://www.ingenuity.com/).

\section{Quantitative real-time PCR}

The mRNA levels of a number of genes known to be important in osteoblast and osteoclast development 


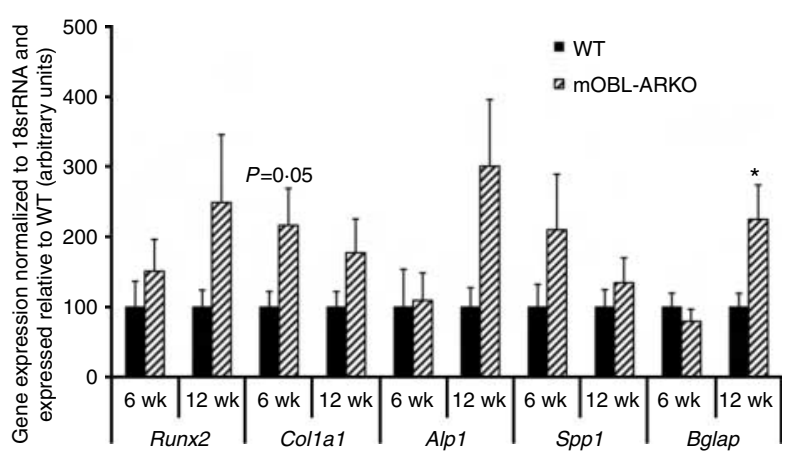

Figure 1 mRNA levels of osteoblast genes in the bones of WT and mOBL-ARKO mice at 6 and 12 weeks of age by Q-PCR. Runx2, runt-related transcription factor 2 (cbfa1); Col1a1, type $1 \propto 1$ collagen; Alp1, alkaline phosphatase 1; Spp1, osteopontin; Bglap, osteocalcin. Mean + s.E.M., $n=16-20$ per group, ${ }^{\star} P<0.05$ vs WT within age group, unpaired Student's $t$-test.

were determined in bone RNA samples of WT and mOBL-ARKOs ( $n=15-20$ per group) using quantitative real-time PCR (Q-PCR). The expression of genes of interest, identified to be androgen responsive by microarray analysis, was also confirmed in these bone RNA samples. Q-PCR was performed in duplicate using $10-75 \mathrm{ng}$ cDNA per $20 \mu \mathrm{l}$ reaction on an Applied Biosystems 7500 Real-Time PCR System, using Applied Biosystems TaqMan gene expression assays (Supplementary Table 1, see section on supplementary data given at the end of this article). Absolute expression was calculated using the $C_{\mathrm{T}}$ method with values for the gene of interest normalized to eukaryotic $18 S \mathrm{rRNA}$ and expressed relative to a reference sample.

\section{Serum biochemistry}

Serum DHT was analyzed by organic solvent extraction and RIA (Beckman Coulter, Fullerton, CA, USA) as described previously (MacLean et al. 2008). The sensitivity of the assay is $0.01 \mathrm{nM}$, the intra-assay coefficient of variation range is $\leq 6 \cdot 2 \%$, the inter-assay coefficient of variation is $\leq 8.5 \%$, and the assay is highly specific for DHT. Serum adiponectin was measured by ELISA according to the manufacturer's instructions (Quantikine; R\&D Systems, Inc., Minneapolis, MN, USA). Fasting serum glucose levels were measured using a GM7 Analox glucose analyser (Helena Laboratories, Beaumont, TX, USA).

\section{Statistical analysis}

To compare the means of two groups, the unpaired Student's $t$-test was used, with Levene's test for homogeneity of variance. To compare more than two groups, data were analyzed by one-way ANOVA, with Tukey's or Tamhane's post hoc tests for equal and unequal variance respectively. All data were analyzed with SPSS for MacOSX except the GO $\chi^{2}$ analysis, which was calculated using the Ingenuity online tool. A $P$ value of $<0.05$ was considered significant.

\section{Results}

\section{Targeted approach}

To identify genes regulated directly or indirectly via the AR, we first used a targeted approach to determine the mRNA levels of genes expressed by osteoblasts at defined stages of development and by osteoclasts in mOBL-ARKOs and WT controls. The mRNA levels of the osteoblast-specific genes, Colla1 $(P=0.05)$ and Bglap $(P<0 \cdot 05)$, were increased twofold in the bones of mOBL-ARKOs compared with WT mice at 6 and 12 weeks of age respectively (Figs 1 and 2). mRNA expression of the osteoclast genes, Ctsk and RANKL, was increased in the bones of mOBL-ARKO by 3.4-fold at 6 weeks of age and by twofold at 12 weeks of age, respectively $(P<0 \cdot 05)$, while the ratio of RANKL:OPG did not differ from WT (Fig. 2).

\section{Microarray analysis}

To identify novel gene targets/pathways activated by the $\mathrm{AR}$ in osteoblasts, we used microarray analysis. In the bones of mOBL-ARKOs, microarray analysis identified 24 genes that were regulated by $\geq 1 \cdot 5$-fold at 6 weeks of age, 374 genes regulated at 12 weeks of age, with 13 genes regulated at both 6 and 12 weeks of age compared with WT (data available at http://www.ebi.ac. uk/arrayexpress/experiments/E-MTAB-1123). Gene ontology mining performed on the androgen-responsive genes identified a number of significantly over-represented

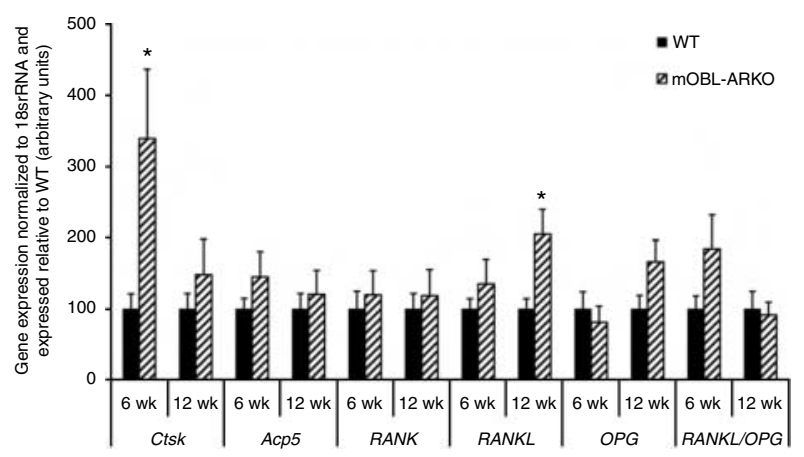

Figure 2 mRNA levels of osteoclast genes in the bones of WT and mOBL-ARKO mice at 6 and 12 weeks of age by Q-PCR. Ctsk, cathepsin K; Acp5, tartrate-resistant acid phosphatase; RANK, receptor activator of nuclear factor $\kappa \mathrm{B}$; RANKL, receptor activator of nuclear factor $\kappa B$ ligand; OPG, osteoprotegerin. Mean + S.E.M., $n=16-20$ per group; ${ }^{*} P<0.05$ vs WT within age group, unpaired Student's $t$-test. 
Table 1 Summary of Top Bio Functions identified by GO analysis from microarray analysis of 24 genes to be over-represented in bones of mOBL-ARKOs at 6 weeks of age $(\geq 1 \cdot 5$-fold)

\section{Name}

Molecular and cellular functions

Cellular growth and proliferation

Cellular development

Gene expression

Cell death

Antigen presentation

Physiological system development and function

Hematological system development and function

Humoral immune response

Tissue development

Hematopoiesis

Connective tissue development and function
$P$ value

$4.7 \times 10^{-5}$ to $4.0 \times 10^{-2}$
$1.2 \times 10^{-4}$ to $3.7 \times 10^{-2}$
$6.2 \times 10^{-4}$ to $2.5 \times 10^{-2}$
$1.9 \times 10^{-3}$ to $4.6 \times 10^{-2}$
$6.8 \times 10^{-3}$ to $8.7 \times 10^{-3}$
$4.7 \times 10^{-5}$ to $3.7 \times 10^{-2}$
$4.7 \times 10^{-5}$ to $2.8 \times 10^{-2}$
$4.7 \times 10^{-5}$ to $9.9 \times 10^{-3}$
$1.2 \times 10^{-4}$ to $3.7 \times 10^{-2}$
$1.9 \times 10^{-3}$ to $1.8 \times 10^{-2}$

functional processes/disorders including cellular growth and proliferation, cellular development, skeletal and muscular system development and function, and carbohydrate metabolism (Tables 1 and 2). Candidate genes representative of these biological processes were chosen for further investigation based on the evidence provided from PubMed searches to support their potential role in the regulation of bone. The regulation of key candidate genes in the bones of mOBL-ARKOs compared with WT mice was confirmed by Q-PCR ( $n=16-20$ per group). A number of genes of interest, whose expression was identified to be altered in mOBL-ARKOs by microarray, could not be confirmed by Q-PCR analysis in a larger cohort of bone cDNA samples (data not shown). In the bones of mOBL-ARKOs, the mRNA expression of genes associated with bone growth and development was upregulated; $G h$ mRNA expression was increased 3·6-fold $(P<0 \cdot 005)$, Wnt4 increased by $2 \cdot 3$-fold $(P<0 \cdot 05)$, Irf4 increased by $2 \cdot 6$-fold $(P<0 \cdot 001)$, and $T g f b 2$ increased by twofold $(P<0.05)$ compared with WT at 12 weeks of age (Fig. 3). ltbp2 gene expression was upregulated $3 \cdot 4$ and $2 \cdot 4$-fold at $6(P<0.005)$ and 12 weeks $(P<0 \cdot 05)$ of age, respectively, in mOBL-ARKOs compared with controls (Fig. 3). Expression of genes involved in carbohydrate metabolism, Dpp4 and Adipoq, were upregulated in mOBL-ARKOs by $2 \cdot 6$-fold at 6 weeks of age $(P<0.05)$ and by $2 \cdot 7$-fold at 12 weeks of age $(P<0.005)$ (Fig. 4).

\section{Androgen deprivation and replacement experiment}

Genes confirmed to be regulated in mOBL-ARKOs were further investigated for their response to androgen deprivation and replacement using an ORX and DHT treatment mouse model. Serum DHT levels were decreased in ORX WT males compared with sham controls (mean \pm s.E.M.; sham: $1 \cdot 55 \pm 0 \cdot 49 \mathrm{nM}, n=11$, vs ORX + vehicle: $0 \cdot 45 \pm 0 \cdot 07 \mathrm{nM}, n=11, P<0 \cdot 05)$. Treatment of ORX males with DHT implants for 10 weeks increased serum DHT levels by 40 -fold (mean \pm s.E.M.; ORX + vehicle: $0 \cdot 45 \pm 0 \cdot 07 \mathrm{nM}, n=11$, vs ORX +DHT: $17 \cdot 79 \pm 2 \cdot 37 \mathrm{nM}, n=13, P<0 \cdot 001)$. As serum estradiol is below the detection limit of $5 \mathrm{pg} / \mathrm{ml}$ in male mice, such measurements were not performed as they would not be informative in ORX mice with or without DHT treatment. A number of genes confirmed to be upregulated in mOBL-ARKOs by Q-PCR were also shown to be increased in WT males following ORX

Table 2 Summary of Top Bio Functions identified by GO analysis from microarray analysis of 374 genes to be over-represented in bones of mOBL-ARKOs at 12 weeks of age $(\geq 1 \cdot 5$-fold $)$

\begin{tabular}{|c|c|}
\hline Name & $P$ value \\
\hline \multicolumn{2}{|l|}{ Molecular and cellular functions } \\
\hline Carbohydrate metabolism & $1.3 \times 10^{-7}$ to $1.3 \times 10^{-2}$ \\
\hline Cellular development & $3.3 \times 10^{-6}$ to $1.3 \times 10^{-2}$ \\
\hline Cellular growth and proliferation & $5.3 \times 10^{-6}$ to $1.3 \times 10^{-2}$ \\
\hline Cell death & $2.0 \times 10^{-5}$ to $1.3 \times 10^{-2}$ \\
\hline Small molecule biochemistry & $2.9 \times 10^{-5}$ to $1.3 \times 10^{-2}$ \\
\hline \multicolumn{2}{|l|}{ Physiological system development and function } \\
\hline Tissue morphology & $8.5 \times 10^{-16}$ to $1.3 \times 10^{-2}$ \\
\hline Skeletal and muscular system development and function & $2.0 \times 10^{-15}$ to $1.3 \times 10^{-2}$ \\
\hline Hematological system development and function & $4.2 \times 10^{-6}$ to $1.3 \times 10^{-2}$ \\
\hline Humoral immune response & $4.2 \times 10^{-6}$ to $1.3 \times 10^{-2}$ \\
\hline Hematopoiesis & $5.9 \times 10^{-6}$ to $1.3 \times 10^{-2}$ \\
\hline
\end{tabular}




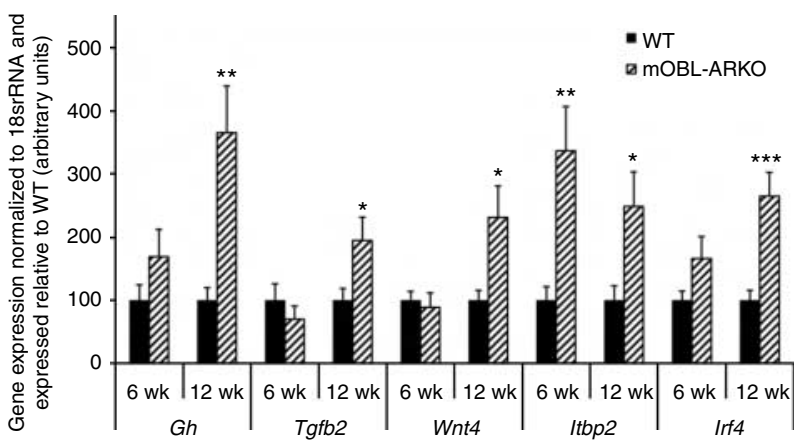

Figure 3 mRNA levels of genes involved in growth and development in the bones of WT and MOBL-ARKO mice at 6 and 12 weeks of age by Q-PCR. Tgfb2, TGFB2; Wnt4, winglessrelated MMTV integration site 4; Itbp2, latent transforming growth factor binding protein 2; Irf4, interferon regulatory factor 4 . Mean + S.E.M., $n=16-20$ per group; ${ }^{\star} P<0.05,{ }^{\star \star} P<0.005$, ${ }^{* \star \star} P<0.001$ vs WT within age group, unpaired Student's $t$-test.

(Fig. 5a, b, c and d). This comprised osteoblast genes, Colla1 and Bglap (Fig. 5a), and those identified by microarray analysis to be involved in growth and development, Gh and Irf4 (Fig. 5c), and carbohydrate metabolism, Adipoq (Fig. 5d). Treatment of ORX males with DHT restored the mRNA levels of these genes to those observed in WT sham-operated controls (Fig. 5a, b, c and d).

\section{Serum adiponectin and glucose}

Serum adiponectin was decreased in mOBL-ARKOs at 6 weeks of age compared with WT $(P<0 \cdot 01)$ but was unchanged at 12 weeks of age (Fig. 6a). Serum glucose was unaffected in mOBL-ARKOs at 6 or 12 weeks of age (Fig. 6b).

\section{Discussion}

It is well established that androgens play an important role in skeletal growth and bone maintenance in males. We have previously shown that the actions of androgens on bone, at least in part, are mediated via the AR located in osteoblasts (Notini et al. 2007, Chiang et al. 2009, MacLean et al. 2010). We have shown using our mOBL-ARKO mouse model that androgens act through the $\mathrm{AR}$ in mineralizing osteoblasts and osteocytes to maintain cortical and trabecular bone by controlling the coordination of bone matrix synthesis and mineralization and by indirectly regulating bone resorption (Chiang et al. 2009). We now extend our studies on male mOBL-ARKO mice in order to identify target genes/pathways within bone that are regulated either indirectly or directly by AR action in mineralizing osteoblasts.
To achieve this aim, we used two approaches. The first was a targeted approach whereby we determined the levels of genes expressed specifically by osteoblasts at different stages of their development and also genes known to be highly expressed by osteoclasts. The second approach was microarray analysis on RNA extracted from whole bone of mOBL-ARKOs and controls to identify possible novel gene targets and pathways responsible for the bone phenotype observed in these mice (Chiang et al. 2009). Our rationale for determining the gene expression profiles in both immature (6 weeks of age) and adult (12 weeks of age) mOBL-ARKOs is that the bone loss in mOBLARKOs was most marked at 6 weeks of age, with an unexpected compensatory increase in osteoblast activity observed in adult mice at 12 weeks of age (Chiang et al. 2009). The rationale for performing microarray analysis on RNA collected from whole bone was to ensure that we had the ability to identify genes that are regulated either indirectly or directly by AR action in mineralizing osteoblasts in both cortical and trabecular bone and in all bone cell types. This was particularly important given that we have previously shown that deletion of the AR specifically in mineralizing osteoblasts in mOBL-ARKOs has not only direct effects on bone formation but also indirect effects on osteoclasts to increase bone resorption, with these effects being observed in both trabecular and cortical bone (Chiang et al. 2009).

Gene ontology mining performed on the androgenresponsive genes identified a number of significantly over-represented functional processes/disorders including those involved in growth and development, in particular those involved in skeletal and muscular system development and function and carbohydrate metabolism. A number of genes identified to have altered expression in the bone of mOBL-ARKOs by microarray analysis could not be confirmed by Q-PCR,

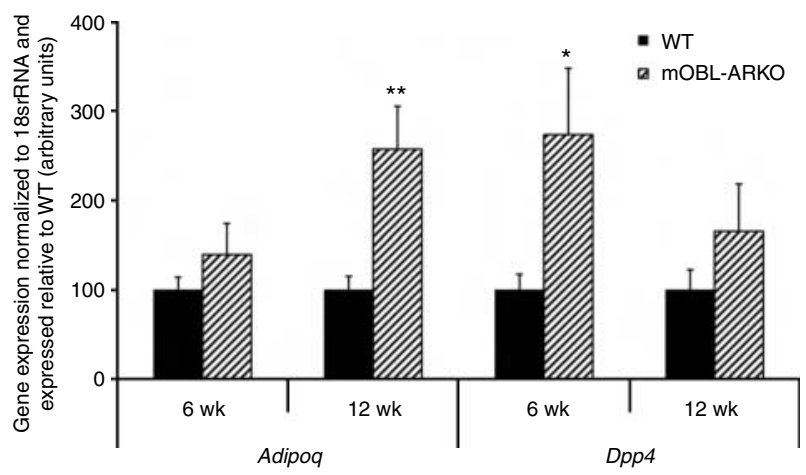

Figure 4 mRNA levels of genes involved in carbohydrate metabolism in the bones of WT and mOBL-ARKOs at 6 and 12 weeks of age by Q-PCR. Adipoq, adiponectin; Dpp4, dipeptidyl peptidase 4. Mean+S.E.M., $n=16-20$ per group; ${ }^{\star} P<0.05$, ${ }^{\star \star} P<0.005$ vs WT within age group, unpaired Student's $t$-test. 


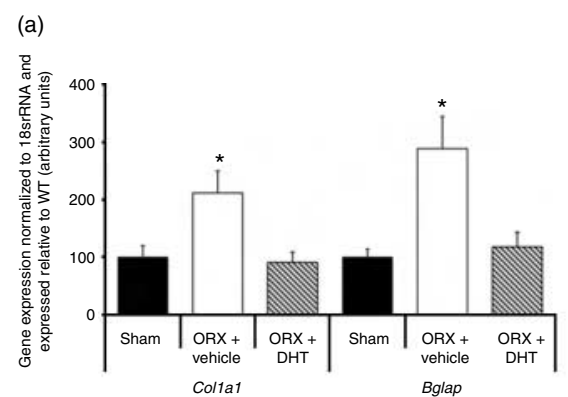

(b)

(c)
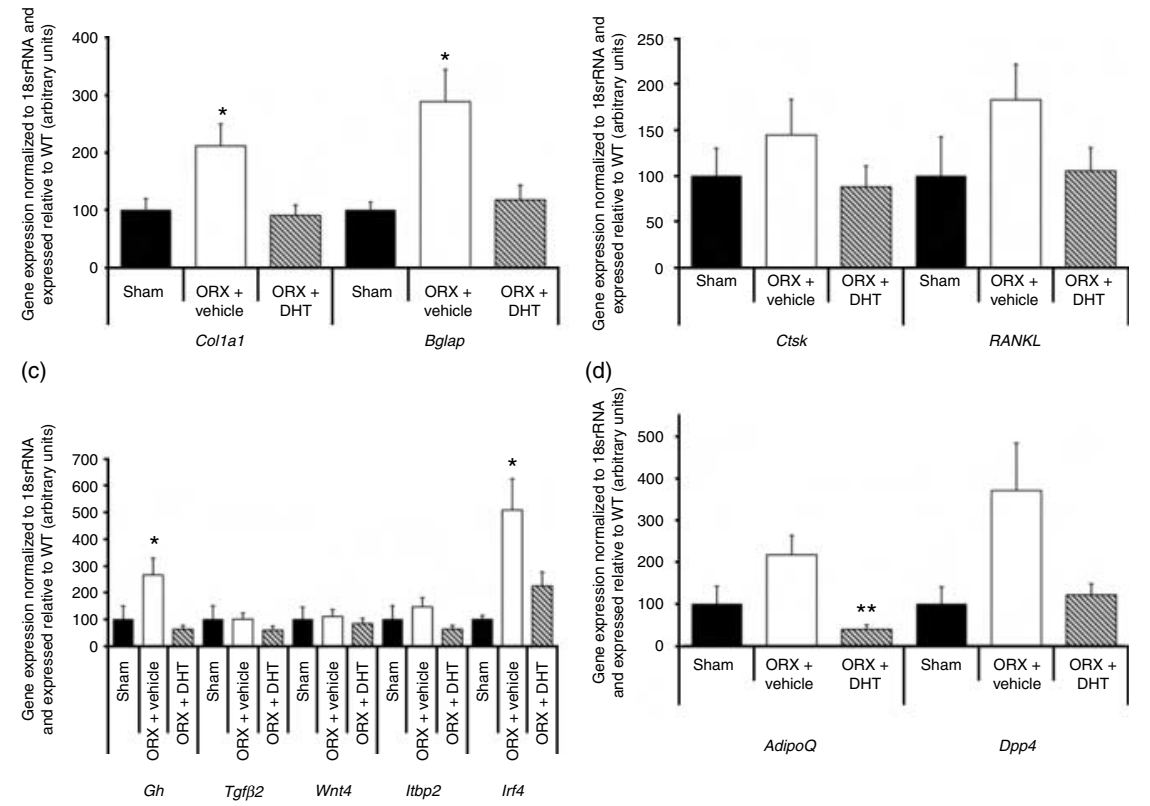

Figure 5 mRNA levels of genes associated with (a) osteoblast development, (b) osteoclasts, (c) growth and development, and (d) carbohydrate metabolism that were altered in $\mathrm{mOBL}$ ARKOs in response to androgen deprivation (ORX WT males + vehicle) and androgen replacement (ORX+DHT). Mean + S.E.M., $n=9-11$ per group; ${ }^{*} P<0.05$ vs WT sham, ${ }^{\star *} P<0.005$ vs ORX + vehicle, ANOVA and post hoc test.

highlighting the importance of confirming all microarray analysis gene regulation data in a larger cohort of RNA samples before drawing conclusions. All the genes discussed below were confirmed to have altered expression in RNA isolated from the whole bones of mOBL-ARKOs compared with controls by Q-PCR with 16-20 samples per group. Given the heterogeneous nature of bone together with the intricate communication network that exists between bone cells, this approach has advantages over using in vitro cultures of isolated osteoblasts from mOBL-ARKOs, as it is a better representation of the bone microenvironment in vivo and also allows the identification of genes indirectly altered in other bone cell types as a result of loss of AR action in mineralizing osteoblasts, such as osteoclasts. As a proof of principal, all genes confirmed to be regulated following their identification by either the targeted or microarray approach were investigated for their androgen responsiveness in an androgen deprivation and replacement male mouse model. ORX led to negligible levels of serum DHT. As mice do not produce adrenal androgens (Payne \& Hales 2004), the ORX mice are completely androgen null and the low levels of DHT detected in these mice must be due to the low level of cross-reactivity of the anti-DHT antibody with other steroid hormones (Yarrow et al. 2010). Treatment of the ORX mice with the nonaromatizable androgen, DHT, resulted in supraphysiological levels of DHT, 40-fold higher than those observed in sham controls. As expected, the expression of a number of genes identified to be upregulated in mOBL-ARKOs (Colla1, Bglap, Gh, Irf4, and Adipoq) was increased following ORX, and treatment of these mice with DHT restored the expression levels to those observed in sham-operated controls. The upregulation of Colla1 and Bglap expression in the bones of ORX males is consistent with the well-established increase in bone turnover and bone loss following ORX in male rodents, which is prevented with DHT treatment (Vanderschueren et al. 1992). As DHT cannot be aromatized to estradiol, these data provide further evidence to support the regulation of the expression of these genes by androgens acting via the $A R$ in mineralizing osteoblasts and osteocytes.

Abnormalities in bone mineralization previously observed in the mOBL-ARKOs were characterized by increased unmineralized bone matrix (osteoidosis) and a reduction in the number of mineralizing surfaces in skeletally immature mOBL-ARKOs. The osteoidosis persisted throughout adulthood in the mOBL-ARKOs despite a compensatory increase in both the extent and the rate of mineralization (Chiang et al. 2009). Consistent with these findings, we identified increases in the expression of genes encoding type $1 \alpha 1$ collagen (Col1a1) and osteocalcin (Bglap), which are expressed during the matrix development and maturation and 

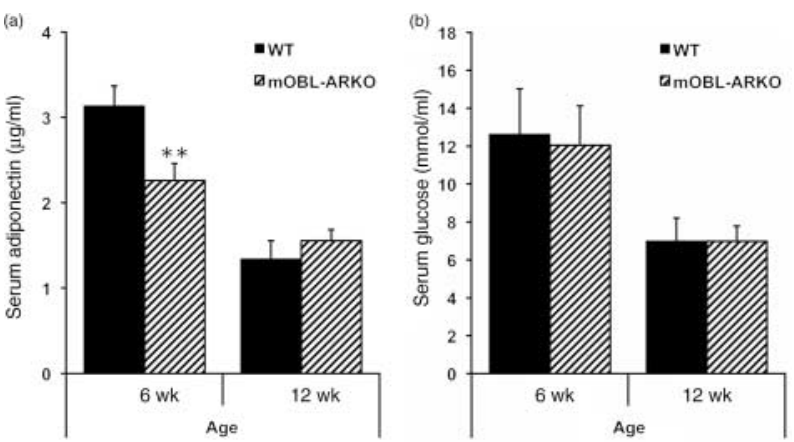

Figure 6 Serum (a) adiponectin $(\mu \mathrm{g} / \mathrm{ml})$ and $(\mathrm{b})$ glucose $(\mathrm{mmol} / \mathrm{l})$ in wild-type (WT) and mOBL-ARKOs at 6 and 12 weeks of age. Mean + S.E.M., $n=9-14$ per group, ${ }^{\star \star} P<0.005$ vs WT within age group, unpaired Student's $t$-test.

mineralization stages of osteoblast development, respectively, in addition to upregulation of the gene encoding latent transforming growth factor binding protein (ltbp2), a structural component of bone matrix. Consistent with the increased bone resorption and subsequent loss of trabeculae and thinning of cortical bone observed in the mOBL-ARKOs (Chiang et al. 2009), the expression of the osteoclast genes, Ctsk and $R A N K L$, were increased in the bones of mOBL-ARKOs compared with controls at 6 weeks of age.

We previously hypothesized that the compensatory increase in mineralization observed in the absence of androgen action in the mineralizing osteoblasts of adult mOBL-ARKOs may be mediated by increased mechanical forces exerted on the fewer remaining trabeculae and/or action via the GH/IGF1 axis (Chiang et al. 2009). In support of this hypothesis, we identified a number of genes known to be associated with increased bone formation that were upregulated in the adult mOBL-ARKOs, including the growth factors, $G h$ and TGFB (Tgfb2), and the osteoblastogenesis stimulatory factor, WNT4 (Wnt4).

$\mathrm{GH}$ in the circulation is derived primarily from the anterior pituitary (Harvey 2010) but is also made locally within bone and acts in an autocrine or paracrine manner to stimulate bone growth (Baker et al. 1992, Harvey 2010). The upregulation of $G h$ expression in the bones of mOBL-ARKOs is consistent with the increase in GH secretion that occurs following AR blockade in males during late puberty (Metzger \& Kerrigan 1993).

Osteoblasts secrete TGFB and deposit it into the bone matrix, which they can then respond to in an autocrine manner (Robey et al. 1987). The major action of TGFB in bone is to increase the proliferation and early differentiation of osteoblasts, while inhibiting terminal differentiation into osteocytes and apoptosis (Bonewald \& Dallas 1994, Karsdal et al. 2002). The increase in $T g f b 2$ expression in the bones of mOBLARKOs is consistent with the increased bone mineral matrix and mineralization in these mice. A possible role of androgens via the $\mathrm{AR}$ in the regulation of $T g f b 2$ expression is supported by the observation that androgen withdrawal increases $T g f b 2$ mRNA in LNCap cells (Knabbe et al. 1993).

Wnt4, which was also upregulated in adult mOBLARKOs, is expressed by bone lining cells and osteocytes and stimulates osteogenic differentiation of mesenchymal stem cells via the noncanonical signaling pathway in vitro and bone formation in vivo (Chang et al. 2007). While it has been shown that WNT4 is the first signaling molecule to influence the sex determination cascade to regulate the development of the female reproductive tract by antagonizing the production of testosterone (Biason-Lauber \& Konrad 2008), to our knowledge, this is the first evidence for a role of androgens acting via the AR in osteoblasts to regulate Wnt4 gene expression within bone.

Of significant interest, we identified two genes involved in carbohydrate metabolism to be upregulated by deletion of the AR in mineralizing osteoblasts and osteocytes. The first was Adipoq, which encodes adiponectin. The CNS contributes directly to the regulation of bone homeostasis via efferent neural pathways (Wong et al. 2008). It has recently been proposed that adiponectin, predominantly a lipidderived adipokine, is one of the key candidates responsible for the cross talk between bone and fat. Supportive evidence for this theory includes the expression of adiponectin receptors by osteoblasts (Berner et al. 2004) and osteoclasts (Oshima et al. 2005), and over-expression of adiponectin in mice leads to increased trabecular bone volume due to decreased bone resorption (Oshima et al. 2005). Interestingly, serum adiponectin levels are inversely related to visceral fat mass (Arita et al. 1999). It has been proposed that this paradoxical relationship is maintained by the inhibition of adiponectin secretion by cytokines and hormones including testosterone (Swarbrick \& Havel 2008) evidenced by the elevated levels of circulating adiponectin in hypogonadal men and ORX mice, which decrease following treatment with testosterone (Lanfranco et al. 2004, Page et al. 2005, Xu et al. 2005). The upregulation of Adipoq expression in bone of the mOBL-ARKOs is consistent with an action of androgens, acting via the $\mathrm{AR}$ in mineralizing osteoblasts to negatively regulate the expression of adiponectin. The increased Adipoq expression within bone of the mOBLARKOs together with the increased mineralization observed in these mice is also consistent with the positive actions through the autocrine/paracrine pathway of locally produced adiponectin within bone to stimulate bone formation (Berner et al. 2004, Shinoda et al. 2006).

Based on our previous observation of increased adiposity and serum adiponectin in global AR knockout mice (Rana et al. 2011), we determined the serum levels 
of adiponectin and fasting glucose in mOBL-ARKOs. In mOBL-ARKOs, serum glucose levels were unaffected; however, adiponectin was decreased at 6 weeks of age, which returned to normal by adulthood. This is perhaps not surprising given that the levels of adiponectin found in the serum do not necessarily reflect the local concentrations found within the bone microenvironment (Berner et al. 2004). While mOBL-ARKOs have normal body weight (Chiang et al. 2009), the mass of different fat pads and the local concentrations of adiponectin within the bone have not been determined. Nonetheless, these findings of the regulation of both circulating adiponectin and Adipoq expression within bone in the absence of AR action in mineralizing osteoblasts are intriguing and warrant further investigation.

The second gene involved in carbohydrate metabolism identified to be upregulated in mOBL-ARKOs was $D p p 4$, which encodes dipeptidyl peptidase 4 (DPP4). DPP4 plays a major role in glucose metabolism by degrading incretins, the gastrointestinal hormones that increase insulin secretion from $\beta$-cells after eating, before the rise in blood glucose (Drucker \& Nauck 2006). Evidence for a role of DPP4 in the regulation of bone metabolism, to date, is limited. DPP4 has been shown to be expressed by cells of the monocytemacrophage lineage, osteosarcomas, and osteoclasts (Dohi et al. 2009), while different DPP4 inhibitors have been shown to have opposite effects on bone mineral density in mice (Kyle et al. 2011). While low circulating levels of testosterone have been implicated to play a role in the pathogenesis of diabetes in humans (Grossmann et al. 2010) and DPP4 has been identified to have actions on bone, the potential role of androgens in the regulation of DPP4 within bone is unknown.

This study is the first step in identifying genes within bone that have altered expression as a result of loss of androgen action via the $\mathrm{AR}$ in mineralizing osteoblasts and osteocytes. The targeted and microarray approaches used in this study identified a number of genes of significant interest. Many of the genes shown to be upregulated in mOBL-ARKOs were consistent with their bone phenotype and the action of androgens via the $\mathrm{AR}$ in mineralizing osteoblasts to regulate matrix synthesis and mineralization (Col1a1, Bglap, Gh, and Tgfb2) and to indirectly inhibit bone resorption (Cstk and RANKL; Chiang et al. 2009), thereby validating our experimental approach. Importantly, this approach also enabled the identification of novel AR gene targets within bone, such as Wnt4, Adipoq, and Dpp4.

In conclusion, androgens act directly via the AR in mineralizing osteoblasts to regulate the expression of genes involved in the development and regulation of osteoblasts, osteoclasts, and skeletal growth, in addition to those involved in energy metabolism.
Future studies targeting these genes and pathways within specific bone cell types using knockdown and over-expression approaches will allow further investigation into the downstream targets of the AR in osteoblasts.

\section{Supplementary data}

This is linked to the online version of the paper at http://dx.doi.org/ 10.1530/JME-12-0014

\section{Declaration of interest}

The authors declare that there is no conflict of interest that could be perceived as prejudicing the impartiality of the research reported.

\section{Funding}

This study was funded by the National Health and Medical Research Council Australia (Project Grant 566503).

\section{Acknowledgements}

The authors would like to thank Dr Helen MacLean, Dr Cherie Chiang, and Maria Chiu for their assistance with this study.

\section{References}

Abu EO, Horner A, Kusec V, Triffitt JT \& Compston JE 1997 The localization of androgen receptors in human bone. Journal of Clinical Endocrinology and Metabolism 82 3493-3497. (doi:10.1210/jc. 82.10.3493)

Arita Y, Kihara S, Ouchi N, Takahashi M, Maeda K, Miyagawa J, Hotta K, Shimomura I, Nakamura T, Miyaoka K et al. 1999 Paradoxical decrease of an adipose-specific protein, adiponectin, in obesity. Biochemical and Biophysical Research Communications 257 79-83. (doi:10.1006/bbrc.1999.0255)

Axell AM, MacLean HE, Plant DR, Harcourt LJ, Davis JA, Jimenez M, Handelsman DJ, Lynch GS \& Zajac JD 2006 Continuous testosterone administration prevents skeletal muscle atrophy and enhances resistance to fatigue in orchidectomized male mice. American Journal of Physiology. Endocrinology and Metabolism 291 E506-E516. (doi:10.1152/ajpendo.00058.2006)

Baker AR, Hollingshead PG, Pitts-Meek S, Hansen S, Taylor R \& Stewart TA 1992 Osteoblast-specific expression of growth hormone stimulates bone growth in transgenic mice. Molecular and Cellular Biology 12 5541-5547. (doi:10.1128/MCB.12.12.5541)

Basaria S \& Dobs AS 2001 Hypogonadism and androgen replacement therapy in elderly men. American Journal of Medicine 110 563-572. (doi:10.1016/S0002-9343(01)00663-5)

Berner HS, Lyngstadaas SP, Spahr A, Monjo M, Thommesen L, Drevon CA, Syversen U \& Reseland JE 2004 Adiponectin and its receptors are expressed in bone-forming cells. Bone 35 842-849. (doi:10.1016/j.bone.2004.06.008)

Biason-Lauber A \& Konrad D 2008 WNT4 and sex development. Sexual Development 2 210-218. (doi:10.1159/000152037)

Bonewald LF \& Dallas SL 1994 Role of active and latent transforming growth factor beta in bone formation. Journal of Cellular Biochemistry 55 350-357. (doi:10.1002/jcb.240550312) 
Chang J, Sonoyama W, Wang Z, Jin Q, Zhang C, Krebsbach PH, Giannobile W, Shi S \& Wang CY 2007 Noncanonical Wnt-4 signaling enhances bone regeneration of mesenchymal stem cells in craniofacial defects through activation of p38 MAPK. Journal of Biological Chemistry 282 30938-30948. (doi:10.1074/jbc. M702391200)

Chiang C, Chiu M, Moore AJ, Anderson PH, Ghasem-Zadeh A, McManus JF, Ma C, Seeman E, Clemens TL, Morris HA et al. 2009 Mineralization and bone resorption are regulated by the androgen receptor in male mice. Journal of Bone and Mineral Research 24 621-631. (doi:10.1359/jbmr.081217)

Colvard DS, Eriksen EF, Keeting PE, Wilson EM, Lubahn DB, French FS, Riggs BL \& Spelsberg TC 1989 Identification of androgen receptors in normal human osteoblast-like cells. PNAS $\mathbf{8 6}$ 854-857. (doi:10.1073/pnas.86.3.854)

Davey RA, Hahn CN, May BK \& Morris HA 2000 Osteoblast gene expression in rat long bones: effects of ovariectomy and dihydrotestosterone on mRNA levels. Calcified Tissue International 67 75-79. (doi:10.1007/s00223001100)

Dohi O, Ohtani H, Hatori M, Sato E, Hosaka M, Nagura H, Itoi E \& Kokubun S 2009 Histogenesis-specific expression of fibroblast activation protein and dipeptidylpeptidase-IV in human bone and soft tissue tumours. Histopathology 55 432-440. (doi:10.1111/j.13652559.2009.03399.x)

Drucker DJ \& Nauck MA 2006 The incretin system: glucagon-like peptide-1 receptor agonists and dipeptidyl peptidase- 4 inhibitors in type 2 diabetes. Lancet 368 1696-1705. (doi:10.1016/S01406736(06)69705-5)

Franz-Odendaal TA, Hall BK \& Witten PE 2006 Buried alive: how osteoblasts become osteocytes. Developmental Dynamics 235 176-190. (doi:10.1002/dvdy.20603)

Grossmann M, Gianatti EJ \& Zajac JD 2010 Testosterone and type 2 diabetes. Current Opinion in Endocrinology, Diabetes $\mathcal{E} O$ Obesity 17 247-256. (doi:10.1097/MED.0b013e32833919cf)

Harvey S 2010 Extrapituitary growth hormone. Endocrine 38 335-359. (doi:10.1007/s12020-010-9403-8)

Karsdal MA, Larsen L, Engsig MT, Lou H, Ferreras M, Lochter A, Delaisse JM \& Foged NT 2002 Matrix metalloproteinase-dependent activation of latent transforming growth factor-beta controls the conversion of osteoblasts into osteocytes by blocking osteoblast apoptosis. Journal of Biological Chemistry 277 44061-44067. (doi:10.1074/jbc.M207205200)

Kasperk CH, Wergedal JE, Farley JR, Linkhart TA, Turner RT \& Baylink DJ 1989 Androgens directly stimulate proliferation of bone cells in vitro. Endocrinology 124 1576-1578. (doi:10.1210/endo-1243-1576)

Kawano H, Sato T, Yamada T, Matsumoto T, Sekine K, Watanabe T, Nakamura T, Fukuda T, Yoshimura K, Yoshizawa T et al. 2003 Suppressive function of androgen receptor in bone resorption. PNAS 100 9416-9421. (doi:10.1073/pnas.1533500100)

Knabbe C, Klein H, Zugmaier G \& Voigt KD 1993 Hormonal regulation of transforming growth factor beta-2 expression in human prostate cancer. Journal of Steroid Biochemistry and Molecular Biology 47 137-142. (doi:10.1016/0960-0760(93)90067-7)

Kyle KA, Willett TL, Baggio LL, Drucker DJ \& Grynpas MD 2011 Differential effects of PPAR-\{gamma\} activation versus chemical or genetic reduction of DPP-4 activity on bone quality in mice. Endocrinology 152 457-467. (doi:10.1210/en.2010-1098)

Lanfranco F, Zitzmann M, Simoni M \& Nieschlag E 2004 Serum adiponectin levels in hypogonadal males: influence of testosterone replacement therapy. Clinical Endocrinology 60 500-507. (doi:10.1111/j.1365-2265.2004.02007.x)

MacLean HE, Chiu WS, Ma C, McManus JF, Davey RA, Cameron R, Notini AJ \& Zajac JD 2008 A floxed allele of the androgen receptor gene causes hyperandrogenization in male mice. Physiological Genomics 33 133-137. (doi:10.1152/physiolgenomics.00260.2007)

MacLean HE, Moore AJ, Sastra SA, Morris HA, Ghasem-Zadeh A, Rana K, Axell AM, Notini AJ, Handelsman DJ, Seeman E et al. 2010
DNA-binding-dependent androgen receptor signaling contributes to gender differences and has physiological actions in males and females. Journal of Endocrinology 206 93-103. (doi:10.1677/JOE-100026)

Metzger DL \& Kerrigan JR 1993 Androgen receptor blockade with flutamide enhances growth hormone secretion in late pubertal males: evidence for independent actions of estrogen and androgen. Journal of Clinical Endocrinology and Metabolism 76 1147-1152. (doi:10.1210/jc.76.5.1147)

Notini AJ, Davey RA, McManus JF, Bate KL \& Zajac JD 2005 Genomic actions of the androgen receptor are required for normal male sexual differentiation in a mouse model. Journal of Molecular Endocrinology 35 547-555. (doi:10.1677/jme.1.01884)

Notini AJ, McManus JF, Moore A, Bouxsein M, Jimenez M, Chiu WS, Glatt V, Kream BE, Handelsman DJ, Morris HA et al. 2007 Osteoblast deletion of exon 3 of the androgen receptor gene results in trabecular bone loss in adult male mice. Journal of Bone and Mineral Research 22 347-356. (doi:10.1359/jbmr.061117)

Oshima K, Nampei A, Matsuda M, Iwaki M, Fukuhara A, Hashimoto J, Yoshikawa H \& Shimomura I 2005 Adiponectin increases bone mass by suppressing osteoclast and activating osteoblast. Biochemical and Biophysical Research Communications 331 520-526. (doi:10.1016/j. bbrc.2005.03.210)

Owen TA, Aronow M, Shalhoub V, Barone LM, Wilming L, Tassinari MS, Kennedy MB, Pockwinse S, Lian JB \& Stein GS 1990 Progressive development of the rat osteoblast phenotype in vitro: reciprocal relationships in expression of genes associated with osteoblast proliferation and differentiation during formation of the bone extracellular matrix. Journal of Cellular Physiology 143 420-430. (doi:10.1002/jcp.1041430304)

Page ST, Herbst KL, Amory JK, Coviello AD, Anawalt BD, Matsumoto AM \& Bremner WJ 2005 Testosterone administration suppresses adiponectin levels in men. Journal of Andrology 26 85-92.

Payne AH \& Hales DB 2004 Overview of steroidogenic enzymes in the pathway from cholesterol to active steroid hormones. Endocrine Reviews 25 947-970. (doi:10.1210/er.2003-0030)

Rana K, Fam BC, Clarke MV, Pang TP, Zajac JD \& MacLean HE 2011 Increased adiposity in DNA binding-dependent androgen receptor knockout male mice associated with decreased voluntary activity and not insulin resistance. American Journal of Physiology. Endocrinology and Metabolism 301 E767-E778. (doi:10.1152/ajpendo. 00584.2010)

Robey PG, Young MF, Flanders KC, Roche NS, Kondaiah P, Reddi AH, Termine JD, Sporn MB \& Roberts AB 1987 Osteoblasts synthesize and respond to transforming growth factor-type beta (TGF-beta) in vitro. Journal of Cell Biology 105 457-463. (doi:10.1083/jcb.105.1.457)

Shinoda Y, Yamaguchi M, Ogata N, Akune T, Kubota N, Yamauchi T, Terauchi Y, Kadowaki T, Takeuchi Y, Fukumoto S et al. 2006 Regulation of bone formation by adiponectin through autocrine/ paracrine and endocrine pathways. Journal of Cellular Biochemistry 99 196-208. (doi:10.1002/jcb.20890)

Swarbrick MM \& Havel PJ 2008 Physiological, pharmacological, and nutritional regulation of circulating adiponectin concentrations in humans. Metabolic Syndrome and Related Disorders 6 87-102. (doi:10.1089/met.2007.0029)

Vanderschueren D, Van Herck E, Suiker AM, Visser WJ, Schot LP \& Bouillon R 1992 Bone and mineral metabolism in aged male rats: short and long term effects of androgen deficiency. Endocrinology 130 2906-2916. (doi:10.1210/en.130.5.2906)

Vanderschueren D, Vandenput L, Boonen S, Lindberg MK, Bouillon R \& Ohlsson C 2004 Androgens and bone. Endocrine Reviews 25 389-425. (doi:10.1210/er.2003-0003)

Venken K, De Gendt K, Boonen S, Ophoff J, Bouillon R, Swinnen JV, Verhoeven G \& Vanderschueren D 2006 Relative impact of androgen and estrogen receptor activation in the effects of androgens on trabecular and cortical bone in growing male mice: a study in the androgen receptor knockout mouse model. Journal of Bone and Mineral Research 21 576-585. (doi:10.1359/jbmr.060103) 
Wiren KM 2005 Androgens and bone growth: it's location, location, location. Current Opinion in Pharmacology 5 626-632. (doi:10.1016/j. coph.2005.06.003)

Wiren KM, Zhang XW, Toombs AR, Kasparcova V, Gentile MA, Harada S \& Jepsen KJ 2004 Targeted overexpression of androgen receptor in osteoblasts: unexpected complex bone phenotype in growing animals. Endocrinology 145 3507-3522. (doi:10.1210/en. 2003-1016)

Wiren KM, Semirale AA, Zhang XW, Woo A, Tommasini SM, Price C, Schaffler MB \& Jepsen KJ 2008 Targeting of androgen receptor in bone reveals a lack of androgen anabolic action and inhibition of osteogenesis: a model for compartment-specific androgen action in the skeleton. Bone 43 440-451. (doi:10.1016/j.bone.2008.04.026)

Wong IP, Zengin A, Herzog H \& Baldock PA 2008 Central regulation of bone mass. Seminars in Cell and Developmental Biology 19 452-458. (doi:10.1016/j.semcdb.2008.08.001)

Xu A, Chan KW, Hoo RL, Wang Y, Tan KC, Zhang J, Chen B, Lam MC, Tse C, Cooper GJ et al. 2005 Testosterone selectively reduces the high molecular weight form of adiponectin by inhibiting its secretion from adipocytes. Journal of Biological Chemistry $\mathbf{2 8 0}$ 18073-18080. (doi:10.1074/jbc.M414231200)

Yarrow JF, Conover CF, Lipinska JA, Santillana CA, Wronski TJ \& Borst SE 2010 Methods to quantify sex steroid hormones in bone: applications to the study of androgen ablation and administration. American Journal of Physiology. Endocrinology and Metabolism 299 E841-E847. (doi:10.1152/ajpendo.00384.2010)

Yeh S, Tsai MY, Xu Q, Mu XM, Lardy H, Huang KE, Lin H, Yeh SD, Altuwaijri S, Zhou X et al. 2002 Generation and characterization of androgen receptor knockout (ARKO) mice: an in vivo model for the study of androgen functions in selective tissues. PNAS 99 13498-13503. (doi:10.1073/pnas.212474399)

Received in final form 30 March 2012

Accepted 23 April 2012

Made available online as an Accepted Preprint 23 April 2012 